\title{
An Update on Subclinical Hypopituitarism
}

\author{
Paula Andujar-Plata ${ }^{1}$, Eva Fernandez-Rodriguez ${ }^{1}$ and Felipe F. Casanueva ${ }^{1,2,3^{*}}$ \\ ${ }^{1}$ Endocrinology Division, Complejo Hospitalario Universitario de Ourense (CHUO), SERGAS, Ourense, 32005, Spain \\ ${ }^{2}$ Departamento de Medicina, Universidad de Santiago de Compostela, Santiago de Compostela, 15706, Spain \\ ${ }^{3}$ Centro de InvestigaciónBiomédicaen Red (CIBER) de FisiopatologíaObesidad y Nutrición, InstitutoSalud Carlos III, Santiago de Compostela, 15706, Spain \\ ${ }^{*}$ Corresponding author: Dr. Felipe F. Casanueva, Endocrinology Division, Hospital Clinico Universitario, Travesía da Choupana s/n. Santiago de Compostela, La \\ Coruña, 15706, Spain, Tel: (+34) 981951245; Fax: (+34) 981951546; E-mail: felipe.casanueva@usc.es
}

Received date: May 25, 2016; Accepted date: June 17, 2016; Published date: June 22, 2016

Copyright: (c) 2016 Andujar-Plata P, et al. This is an open-access article distributed under the terms of the Creative Commons Attribution License, which permits unrestricted use, distribution, and reproduction in any medium, provided the original author and source are credited.

\begin{abstract}
Subclinical deficiency of pituitary hormones represents an intermediate situation among normal pituitary secretion and overt hypopituitarism. Clinical hypopituitarism is associated with impaired morbidity and mortality, but there are not many studies on these topics in the subclinical setting. Moreover, clinical manifestations and diagnosis criteria are not well defined, so this entity is probably an underdiagnosed disorder. Long-term controlled studies are needed to establish a correct definition of subclinical hypopituitarism and to know its clinical implications, optimal methods of diagnosis, and indications for substitutive treatment. This review will focus on the evidence related to epidemiology, clinical manifestations, diagnosis, and treatment of subclinical hypopituitarism.
\end{abstract}

Keywords: Hypopituitarism; Subclinical hypopituitarism; Pituitary insufficiency; Partial growth hormone deficiency; Partial adrenocorticotropic hormone deficiency

\section{Introduction}

Hypopituitarism is the insufficient secretion of one or more pituitary hormones caused by pituitary and/or hypothalamic disorders [1]. Hormonal deficiency can be isolated or multiple, with the gonadotropic and somatotropic axes the most frequently affected. Clinical manifestations associated to hypopituitarism are often nonspecific and will depend on the underlying disease, age, rate of onset, and degree of hormonal defect. The clinical importance of hypopituitarism is its association with increased mortality compared with the general population and its association with increased morbidity [2-7]. In fact, changes in body composition, glucose intolerance, hypertension, or altered lipid profile have been detected in these patients $[8,9]$.

In clinical practice, we can observe intermediate situations between established hormone deficiencies and normal pituitary function, which could be considered milder or subclinical forms of hypopituitarism. These conditions, although theoretically would not cause clear symptoms, could be related to the mild impairment of morbidity and mortality as clinical hypopituitarism. However, there is no consensus on the methods of diagnosis and treatment in these subclinical cases.

In this article, we review the epidemiology, clinical manifestations, diagnosis, and treatment of subclinical hormone pituitary deficiencies.

\section{Epidemiology of Subclinical Hypopituitarism}

There are few data available about the prevalence and incidence of hypopituitarism in the general population. In a well-defined population in the northwest of Spain, our group reported a prevalence of hypopituitarism of 37.5 cases per 100,000 inhabitants and an incidence of 2.07 cases per 100,000 inhabitants per year over a period of 10 years (2000-2009) [10].

Data about the epidemiology of subclinical hypopituitarism have not been reported in the general population, although there are studies evaluating subclinical pituitary deficiencies in some specific subgroups of patients. For example, subclinical hypopituitarism was detected in $29 \%$ of patients evaluated after 6 to 9 months of a traumatic brain injury and in $77 \%$ of patients treated with cerebral radiotherapy [11]. There are studies that evaluated some isolated subclinical deficiencies. Subclinical thyroid-stimulating hormone (TSH) deficiency was reported in $20.3 \%$ of patients who were previously irradiated because of head and neck tumors [12] and in $38 \%$ of patients with type 2 diabetes [13], using the thyrotropic releasing hormone (TRH) test for diagnosis.

As previously mentioned, subclinical hypopituitarism does not produce symptoms that can be seen, and the methods for diagnosis are not well established. These conditions probably make subclinical hypopituitarism an underdiagnosed disorder.

\section{Causes of Subclinical Hypopituitarism}

The etiology of subclinical hypopituitarism is the same as that of clinical hypopituitarism [14] (Table 1). In adults, the most common cause is a pituitary adenoma or its treatment (surgery or radiotherapy). Benign pituitary adenomas, which are the most frequent pituitary masses, and particularly macroadenomas $(\geq 1 \mathrm{~cm})$ are commonly associated with hormone deficiencies. Probable mechanisms include the compression of normal pituitary tissue, compression of the blood flow, and interruption of hypothalamic-pituitary communication.

Although pituitary surgery is sometimes associated with some degree of recovery in pituitary function, it can be a cause of hormone deficit [15]. Tumor size, tumor infiltration, or surgeon experience are some factors involved in the development of hypopituitarism. Radiotherapy is another cause of hypopituitarism, and its effect is dose-dependent. Newer methods of irradiation can lower the 
Page 2 of 5

prevalence of subclinical hypopituitarism, although there is still risk involved [16]. Other possible causes of subclinical hypopituitarism include traumatic brain injury, Sheehan's syndrome, infiltrative and immunological diseases, and genetic disorders.

\begin{tabular}{|c|c|}
\hline \multicolumn{2}{|c|}{ Pituitary tumours } \\
\hline- & Adenomas \\
\hline- & Other pituitary tumours \\
\hline \multicolumn{2}{|c|}{ Parasellar tumours } \\
\hline- & Craniopharyngiomas \\
\hline- & Chordomas \\
\hline- & Germinomas \\
\hline- & Meningiomas \\
\hline- & Gliomas \\
\hline- & Metastases \\
\hline- & Others \\
\hline \multicolumn{2}{|c|}{ Brain injury } \\
\hline- & Neurosurgery \\
\hline - & Radiotherapy \\
\hline- & Traumatic brain injury \\
\hline \multicolumn{2}{|c|}{ Vascular disease } \\
\hline- & Pituitary apoplexy \\
\hline - & Sheehan's syndrome \\
\hline- & Subarachnoid haemorrhage \\
\hline - & Stroke \\
\hline \multicolumn{2}{|c|}{ Infiltrative and immunological disease } \\
\hline- & Sarcoidosis \\
\hline- & Tuberculosis \\
\hline - & Histiocytosis \\
\hline- & Haemochromatosis \\
\hline- & Lymphocytic hypophysitis \\
\hline \multicolumn{2}{|c|}{ Infections } \\
\hline- & Meningitis \\
\hline- & Encephalitis \\
\hline- & Abscess \\
\hline \multicolumn{2}{|r|}{$\begin{array}{l}\text { Genetic causes: mutations in PROP1, PIT1, HESX1, LHX4, LHX3, GH, Kallmar } \\
\text { syndrome }\end{array}$} \\
\hline \multicolumn{2}{|c|}{ Primary empty sella } \\
\hline & \\
\hline
\end{tabular}

Table 1: Causes of subclinical hypopituitarism.

\section{Clinical Manifestations of Subclinical Hypopituitarism}

\section{Subclinical growth hormone deficiency}

Clinical manifestations of subclinical hypopituitarism varied based on the age of onset, although the clinical course is usually insidious and without specific symptoms, especially in adults.

In children, the main feature of growth hormone deficiency (GHD) is decreased growth velocity and short height. However, in adulthood, this deficiency can be unrecognized, because the symptoms can be nonspecific. Adults with severe GHD can show changes in body composition with increased fat mass and decreased muscle mass, reduced bone mineral density, metabolic changes (glucose intolerance and altered lipid profile), cardiac changes with premature atherosclerosis and low energy, and reduced quality of life [17-21].

Patients with subclinical GHD could present some of the clinical manifestations of severe GHD but with less intensity. It has been shown that patients with intermediate values in stimulation tests present changes in body composition at an intermediate degree between healthy subjects and patients with severe GHD. Studies of body composition have demonstrated that subjects with subclinical GHD have increased fat mass, reduced lean body mass, and increased skin-fold thickness [22]. This intermediate state has been also associated with impaired insulin sensitivity, impaired lipid profile, and carotid intima-media thickness [23,24]. These changes seem to be related to IGF-I levels.

Another study found that, compared with healthy people, patients who were insufficient in growth hormone $(\mathrm{GH})$ had higher levels of plasminogen activator inhibitor type-I (PAI-I), suggesting an increased cardiovascular risk [25]. A more recent study showed a correlation among the GH axis, the visceral adiposity index, and cardiometabolic risk; thus, apparently healthy patients could have some degree of visceral adipose dysfunction associated with GH and IGF-I levels, but without overt GHD [26]. However, more investigations are needed to support the association between subclinical GHD and increased cardiovascular risk.

\section{Subclinical gonadotropin deficiency}

Symptoms of follicle stimulating hormone/luteinizing hormone (FSH/LH) deficiency depend on the age at onset. Before the age of puberty, males with FSH/LH deficiency have small penises and testes, and women with FSH/LH deficiency have primary amenorrhea with the absence of breast development. In adulthood, males show impaired sexual function, reduction of testicular size, infertility, and weakness, and women have menstrual irregularities or amenorrhoea and infertility.

Subclinical gonadotropin deficiency is difficult to establish in women by clinical features, because normal menstruation would exclude it. However, men with subclinical gonadotropin deficiency can have mild symptoms such as low sexual desire, erectile dysfunction, and poor morning erection or fatigue, in relation with testosterone levels [27].

\section{Subclinical adrenocorticotropic hormone deficiency}

Chronic corticotropin deficiency usually causes weight loss and lethargy, although it can be asymptomatic if cortisol production is enough for day-to-day activity. Therefore, patients with subclinical 
Page 3 of 5

adrenocorticotropic hormone (ACTH) deficiency will probably present symptoms only with concomitant stress or illness, when an increase in cortisol secretion is required. In these situations, patients will present typical symptoms of acute deficiency: nausea, vomiting, weakness, hypotension and fever, abdominal pain, or hypovolemic shock in more severe cases.

\section{Subclinical thyroid-stimulating hormone deficiency}

Subclinical hypothyroidism could be associated with similar symptoms of overt deficiency: lack of energy, weakness, cold intolerance, or constipation. In children, undiagnosed hypothyroidism can be associated with mental and growth retardations, but mild congenital TSH deficiency based on one patient diagnosed at 6 years of age did not shown any impact on intellectual status or mental development [28].

Subclinical primary hypothyroidism has been associated with higher frequency of hypercholesterolemia, atherosclerosis, and coronary heart disease, and with increased risk of coronary heart events (especially in those with TSH $>10 \mathrm{mUI} / \mathrm{L}$ ) [29]. Nevertheless, no studies are available as yet that evaluate the influence of milder TSH deficiencies on the cardiovascular or metabolic systems.

\section{Subclinical prolactin deficiency}

Clinically, prolactin (PRL) deficiency is only characterized by the impossibility to puerperal lactogenesis [30]. Most likely, subclinical deficiency does not cause any symptoms.

\section{Diagnosis of Subclinical Hypopituitarism}

\section{Subclinical growth hormonedeficiency}

Diagnosis of GHD usually requires a stimulation test [31], although it is not necessary in situations with known structural pituitary disease, the presence of three other hormones deficiencies, and a low IGF-I level. GHD can be interpreted as a continuum with a GH response to a provocative test range from a normal GH response to severe GHD (Table 2). The insulin tolerance test is the gold standard for diagnosis, and a peak $\mathrm{GH}$ response $<3 \mu \mathrm{g} / \mathrm{L}$ is indicative of severe deficiency in adults [32], whereas a response over $7 \mu \mathrm{g} / \mathrm{L}$ is considered normal. Peaks of GH response between these values represent intermediate conditions of GHD.

\begin{tabular}{|l|l|l|l|}
\hline Test & Normal peak of GH response $(\boldsymbol{\mu g} / \mathbf{L})$ & Severe deficiency $(\boldsymbol{\mu g} / \mathbf{L})$ & Probably subclinical deficiency $(\boldsymbol{\mu g} / \mathbf{L})$ \\
\hline Insulin tolerance test & $>7$ & $<3$ & $3-7$ \\
\hline GHRH-arginine test & $>16.5$ & $<9.1$ & $9.1-16.5$ \\
\hline GHRH-GHRP6 test & $>20$ & $<10$ & $10-20$ \\
\hline
\end{tabular}

Table 2: Stimulation tests for diagnosis of GH deficiency.

The growth hormone releasing hormone (GHRH)-arginine test is also employed for diagnosis with similar sensitivity and specificity than theinsulin tolerance test. A peak of GH below $9.1 \mu \mathrm{g} / \mathrm{L}$ is necessary for GHD diagnosis, and it is excluded when the GH response is $>16.5$ $\mu \mathrm{g} / \mathrm{L}$. Intermediate values would suggest mild impairment of $\mathrm{GH}$ secretion $[33,34]$. These cutoffs values are dependent on body mass index.

Another provocative test employed in the diagnosis of GHD is the GHRH-GHRP6 test, which confirms diagnosis of GHD if the GH peak is less than $10 \mu \mathrm{g} / \mathrm{L}$ and excludes deficiency if it is $>20 \mu \mathrm{g} / \mathrm{L}$ [35]. Again, levels between 10 and $20 \mu \mathrm{g} / \mathrm{L}$ could represent subclinical deficiency.

Besides the stimulation tests, other parameters can reflect $\mathrm{GH}$ secretion as stimulated UC (area under curve) GH secretion. Values above 1000 are indicative of normal secretion, and values less than 250 indicate a diagnosis of GHD; results between 250 and 1000 would indicate subclinical secretion [36].

IGF-I levels have not showed utility for subclinical GHD diagnosis, because low levels do not discriminate between normal and impaired secretion [37]. However, a recent study has suggested that IGF-I SDS (standard deviation score) can be used as marker of somatotropin function and of hypopituitary severity [38], although more research is needed specifically in the subclinical setting.

In children, subclinical GHD is more difficult to define, although there is at least one case of a child diagnosed after an insulin tolerance test, in whom growth and development was normal [39].

\section{Subclinical gonadotropin deficiency}

Hypogonadotropic hypogonadism is diagnosed with a low serum testosterone and/or estradiol concentration and the absence of increased FSH and LH. However, the diagnosis of subclinical states is difficult to define.

In women, normal menstruation cycles exclude gonadotropin deficiency, and there is not a cutoff that establishes subclinical deficiency in patients with normal menstruation. In men, subclinical deficiency would be defined as normal testosterone levels with FSH or $\mathrm{LH}$ below the 5 th percentile that may be associated with the initial symptoms previously described [40].

\section{Subclinical adrenocorticotropic hormone deficiency}

Low cortisol levels in the morning of $<80 \mathrm{nmol} / \mathrm{L}$ indicate complete ACTH deficiency, whereas levels $>400 \mathrm{nmol} / \mathrm{L}$ are completely normal. A subclinical corticotropic deficiency would be characterized by normal basal cortisol and ACTH levels, but with an insufficient response to the stimulation test $(<500 \mathrm{nmol} / \mathrm{L})$. The insulin tolerance test is the gold standard for detection of central adrenal failure [41], although the low-dose ACTH stimulation test $(1 \mu \mathrm{g})$ has demonstrated a strong correlation with the ITT with fewer side effects [42]. The high dose of ACTH, $250 \mu \mathrm{g}$, can be also used but it is less sensitive for early diagnosis of chronic ACTH deficiency with normal basal cortisol levels. An optimal threshold for subclinical deficiency with this test has not been established. 
In subjects with traumatic brain injury, subclinical ACTH deficiency has been also defined as basal ACTH or cortisol levels below the 5th percentile [39], but without sufficient evidence.

\section{Subclinical thyroid-stimulating hormonedeficiency}

In contrast with the other axis, stimulation tests are not used in clinical practice to diagnosis TSH deficiency, so subclinical cases can go unrecognized. The TRH test would be an option to detect intermediate defects. In fact, in patients with diabetes type 2 without pituitary disease and normal basal levels of TSH and free T4 and T3, this test detected impaired TSH secretion in approximately $38 \%$ of patients, considered as subclinical hypopituitarism [13].

In patients with traumatic brain damage, subclinical TSH deficiency has been defined as low free-T4 $\left(<5^{\text {th }}\right.$ percentile) with normal total-T4 or vice versa [39].

\section{Subclinical PRL deficiency}

The TRH test can be used for PRL diagnosis in patients with low PRL levels. A Turkish study showed that the TRH test was more compatible with postpartum agalactia than with PRL levels to detect lactotroph deficiency, particularly in patients with PRL basal levels between 4 and $7.8 \mathrm{ng} / \mathrm{ml}[43]$.

\section{Treatment of subclinical hypopituitarism}

There is not much data about GH treatment in subclinical defects. A Brazilian study showed that treatment with recombinant human GH in children with mild GHD (defined as GH peak of 5 to $10 \mathrm{ng} / \mathrm{mL}$ after the stimulation test) achieved height gain. Height-SDS after the first year of treatment was higher in children with mild deficiency compared with those with severe deficiency, but no difference was found at the last assessment. Differences in GH doses were not observed [44].

Regarding subclinical ACTH deficiency, there is a study that concludes that conventional replacement with $10 \mathrm{mg}$ twice daily of hydrocortisone in these patients produces hypercortisolemia [45], so treatment should avoid physiological conditions without stress.

There are no data for or against substitutive treatment in patients with subclinical TSH and with gonadotropin deficiency. Long-term randomized studies analyzing the impact of substitutive treatment in subclinical deficiencies are needed.

In conclusion, subclinical hypopituitarism is an entity not well defined and probably underdiagnosed because of the lack of specific symptoms and well-defined criteria for diagnosis. Long-term controlled studies are needed to investigate the main symptoms of these patients, the implications in morbidity and mortality, the best method for diagnosis, and the specific cut-offs and need/benefits of substitutive treatment.

\section{Acknowledgement}

This work was supported by grants from the Fondo de Investigacion Sanitaria (PI14/01012), and CIBER Fisiopatologia de la Obesidad y Nutricion (CIBERobn; CB06/003), Instituto de Salud Carlos III (ISCIII)-FEDER, Subdireccion General de Evaluacion y Fomento de la Investigacion, Spain.

\section{References}

1. Toogood AA, Stewart PM (2008) Hypopituitarism: clinical features, diagnosis, and management. Endocrinol Metab Clin North Am 37: 235-261.

2. Rosén T, Bengtsson BA (1990) Premature mortality due to cardiovascular disease in hypopituitarism. Lancet 336: 285-288.

3. Bates AS, Van't Hoff W, Jones PJ, Clayton RN (1996) The effect of hypopituitarism on life expectancy. J Clin Endocrinol Metab 81: 1169-1172.

4. Tomlinson JW, Holden N, Hills RK, Wheatley K, Clayton RN, et al. (2001) Association between premature mortality and hypopituitarism. West Midlands Prospective Hypopituitary Study Group. Lancet 357: 425-431.

5. Lindholm J, Nielsen EH, Bjerre P, Christiansen JS, Hagen C, et al. (2006) Hypopituitarism and mortality in pituitary adenoma. Clin Endocrinol (Oxf) 65: 51-58.

6. Bülow B, Hagmar L, Mikoczy Z, Nordström CH, Erfurth EM (1997) Increased cerebrovascular mortality in patients with hypopituitarism. Clin Endocrinol (Oxf) 46: 75-81.

7. Erfurth EM, Bülow B, Hagmar LE (2000) Is vascular mortality increased in hypopituitarism? Pituitary 3: 77-81.

8. Shahi M, Beshyah SA, Hackett D, Sharp PS, Johnston DG, et al. (1992) Myocardial dysfunction in treated adult hypopituitarism: a possible explanation for increased cardiovascular mortality. Br Heart J 67: 92-96.

9. Kaji H, Iida K, Takahashi Y, Okimura Y, Chihara K (2007) Hormone replacement therapy and vascular risk disorders in adult hypopituitarism. Endocr J 54: 239-245.

10. Fernandez-Rodriguez E, Lopez-Raton M, Andujar P, Martinez-Silva IM, Cadarso-Suarez C, et al (2013) Epidemiology, mortality rate and survival in a homogeneous population of hypopituitary patients. Clin Endocrinol (Oxf) 78: 278-284.

11. Taphoorn MJ, Heimans JJ, van der Veen EA, Karim AB (1995) Endocrine functions in long-term survivors of low-grade supratentorial glioma treated with radiation therapy. J Neurooncol 25: 97-102.

12. Bhandare N, Kennedy L, Malyapa RS, Morris CG, Mendenhall WM (2007) Primary and central hypothyroidism after radiotherapy for headand-neck tumors. Int J Radiat Oncol Biol Phys 68: 1131-1139.

13. Small M, Cohen HN, MacLean JA, Beastall GH, MacCuish AC (1986) Impaired thyrotrophin secretion following the administration of thyrotrophin-releasing hormone in type II diabetes mellitus. Postgrad Med J 62: 445-448.

14. Ascoli P, Cavagnini F (2006) Hypopituitarism. Pituitary 9: 335-342.

15. Nomikos P, Ladar C, Fahlbusch R, Buchfelder M (2004) Impact of primary surgery on pituitary function in patients with non-functioning pituitary adenomas -- a study on 721 patients. Acta Neurochir (Wien) 146: 27-35.

16. Xu Z, Lee Vance M, Schlesinger D, Sheehan JP (2013) Hypopituitarism after stereotactic radiosurgery for pituitary adenomas. Neurosurgery 72 : 630-637.

17. De Boer H, Blok GJ, Voerman HJ, De Vries PM, van der Veen EA (1992) Body composition in adult growth hormone-deficient men, assessed by anthropometry and bioimpedance analysis. J Clin Endocrinol Metab 75: 833-837.

18. Beshyah SA, Gelding SV, Andres C, Johnston DG, Gray IP (1995) Betacell function in hypopituitary adults before and during growth hormone treatment. Clin Sci (Lond) 89: 321-328.

19. de Boer H, Blok GJ, Voerman HJ, Phillips M, Schouten JA (1994) Serum lipid levels in growth hormone-deficient men. Metabolism 43: 199-203.

20. Markussis V, Beshyah SA, Fisher C, Sharp P, Nicolaides AN, et al. (1992) Detection of premature atherosclerosis by high-resolution ultrasonography in symptom-free hypopituitary adults. Lancet 340: 1188-1192. 
21. Merola B, Cittadini A, Colao A, Longobardi S, Fazio S, et al. (1993) Cardiac structural and functional abnormalities in adult patients with growth hormone deficiency. J Clin Endocrinol Metab 77: 1658-1661.

22. Murray RD, Adams JE, Shalet SM (2004) Adults with partial growth hormone deficiency have an adverse body composition. J Clin Endocrinol Metab 89: 1586-1591.

23. Murray RD, Shalet SM (2005) Insulin sensitivity is impaired in adults with varying degrees of GH deficiency. Clin Endocrinol (Oxf) 62: 182-188.

24. Colao A, Di Somma C, Spiezia S, Rota F, Pivonello R, et al. (2006) The natural history of partial growth hormone deficiency in adults: a prospective study on the cardiovascular risk and atherosclerosis. J Clin Endocrinol Metab 91: 2191-2200.

25. Murray RD, Wieringa G, Lawrance JA, Adams JE, Shalet SM (2010) Partial growth hormone deficiency is associated with an adverse cardiovascular risk profile and increased carotid intima-medial thickness. Clin Endocrinol (Oxf) 73: 508-515.

26. Di Somma C, Ciresi A, Amato MC, Savastano S, Savanelli MC, et al. (2015) Alteration of the growth hormone axis, visceral fat dysfunction, and early cardiometabolic risk in adults: the role of the visceral adiposity index. Endocrine 49: 492-502.

27. Wu FC, Tajar A, Beynon JM, Pye SR, Silman AJ, et al. (2010) Identification of late-onset hypogonadism in middle-aged and elderly men. N Engl J Med 363: 123-135.

28. Smail PJ, Isles TE, Ackroyd RS (1979) A boy with low-TSH hypothyroidism. Arch Dis Child 54: 475-477.

29. Rodondi N, den Elzen WP, Bauer DC, Cappola AR, Razvi S, et al. (2010) Subclinical hypothyroidism and the risk of coronary heart disease and mortality. JAMA 304: 1365-1374.

30. Zargar AH, Masoodi SR, Laway BA, Shah NA, Salahudin M (1997) Familial puerperal alactogenesis: possibility of a genetically transmitted isolated prolactin deficiency. Br J Obstet Gynaecol 104: 629-631.

31. Ho KK1; 2007 GH Deficiency Consensus Workshop Participants (2007) Consensus guidelines for the diagnosis and treatment of adults with $\mathrm{GH}$ deficiency II: a statement of the GH Research Society in association with the European Society for Pediatric Endocrinology, Lawson Wilkins Society, European Society of Endocrinology, Japan Endocrine Society, and Endocrine Society of Australia. Eur J Endocrinol 157: 695-700.

32. [No authors listed] (1998) Consensus guidelines for the diagnosis and treatment of adults with growth hormone deficiency: summary statement of the Growth Hormone Research Society Workshop on Adult Growth Hormone Deficiency. J Clin Endocrinol Metab 83: 379-381.

33. Colao A, Di Somma C, Pivonello R, Loche S, Aimaretti G, et al. (1999) Bone loss is correlated to the severity of growth hormone deficiency in adult patients with hypopituitarism. J Clin Endocrinol Metab 84: 1919-1924.

34. Colao A, Cerbone G, Pivonello R, Aimaretti G, Loche S, et al. (1999) The growth hormone $(\mathrm{GH})$ response to the arginine plus $\mathrm{GH}$-releasing hormone test is correlated to the severity of lipid profile abnormalities in adult patients with GH deficiency. J Clin Endocrinol Metab 84: 1277-1282.

35. Popovic V, Leal A, Micic D, Koppeschaar HP, Torres E, et al. (2000) GHreleasing hormone and GH-releasing peptide- 6 for diagnostic testing in GH-deficient adults. Lancet 356: 1137-1142.

36. Koppeschaar HP, Popovic V, Leal A, Otero XL, Torres E, et al. (2004) Growth hormone $(\mathrm{GH})$ peaks versus areas under the curve in the diagnosis of adult GH deficiency: analysis of the variables provided by the GHRH + GHRP-6 test. Pituitary 7: 15-20.

37. Mitchell H, Dattani MT, Nanduri V, Hindmarsh PC, Preece MA, et al. (1999) Failure of IGF-I and IGFBP-3 to diagnose growth hormone insufficiency. Arch Dis Child 80: 443-447.

38. Tirosh A,2, Toledano Y2,3, Masri-Iraqi H, et al. (2016) IGF-I levels reflect hypopituitarism severity in adults with pituitary dysfunction. Pituitary .

39. Zimmerman TS, White MG, Daughaday WH, Goetz FC (1967) Hypopituitarism with normal or increased height. Report of two cases, with measurement of plasma growth hormone levels. Am J Med 42: 146-150.

40. Bavisetty S, Bavisetty S, McArthur DL, Dusick JR, Wang C, et al. (2008) Chronic hypopituitarism after traumatic brain injury: risk assessment and relationship to outcome. Neurosurgery 62: 1080-1093.

41. Endert E, Ouwehand A, Fliers E, Prummel MF, Wiersinga WM (2005) Establishment of reference values for endocrine tests. Part IV: Adrenal insufficiency. Neth J Med 63: 435-443.

42. Thaler LM, Blevins LS Jr. (1998) The low dose (1-microg) adrenocorticotropin stimulation test in the evaluation of patients with suspected central adrenal insufficiency. J Clin Endocrinol Metab 83: 2726-2729.

43. Diri H, Tanriverdi F, Karaca Z, Senol S, Unluhizarci K, et al. (2014) Extensive investigation of 114 patients with Sheehan's syndrome: a continuing disorder. Eur J Endocrinol 171: 311-318.

44. Cardoso DF, Martinelli CE Jr2, Campos VC, Gomes ES, Rocha IE, et al. (2014) Comparison between the growth response to growth hormone (GH) therapy in children with partial GH insensitivity or mild GH deficiency. Arq Bras Endocrinol Metabol 58: 23-29.

45. Agha A, Liew A, Finucane F, Baker L, O'Kelly P, et al. (2004) Conventional glucocorticoid replacement overtreats adult hypopituitary patients with partial ACTH deficiency. Clin Endocrinol (Oxf) 60: 688-693. 